\title{
Amaurosis-hypertrichosis syndrome
}

INSERM

\section{Source}

INSERM. (1999). Orphanet: an online rare disease and orphan drug data base.

Amaurosis-hypertrichosis syndrome. ORPHA:1021

Amaurosis hypertrichosis is characterised by severe retinal dystrophy marked by visual impairment and profound photophobia without night blindness. Eye examination suggested a cone-rod type of cong enital amaurosis. Trichomegaly, bushy eyebrows with synophyrys, and excessive facial and body hair were also reported. The syndrome has been described in two female cousins both born to consanguineous parents. 